\title{
Near Term Pregnancy in a Patient with Total Uterine Prolapse
}

\author{
Farahnaz Farzaneh ${ }^{1, *}$ \\ ${ }^{1}$ Department of Obstetrics and Gynecology, Infectious Diseases and Tropical Medicine Research Center, Zahedan University of Medical Sciences, Zahedan, Iran \\ "Corresponding author: Farahnaz Farzaneh, Department of Obstetrics and Gynecology, Infectious Diseases and Tropical Medicine Research Center, Zahedan University of \\ Medical Sciences, Zahedan, Iran. E-mail: farahnaz1826@yahoo.com
}

Received 2015 September 12; Revised 2016 February 07; Accepted 2016 December 06.

\begin{abstract}
Uterine prolapse is herniation of the pelvic organ to vaginal walls or beyond the vaginal, walls as well as it is the most common gynecologic problem that has made by stretching and weakening of muscles and connective tissues. Incidence of total and partial uterine prolapse is around one per 10000 to 15000 deliveries. This study is about a 33-year-old Iranian (Balouch lady) G5P4L4 who had been reffered to maternal ward of Emam Ali hospital of Zahedan city in the 35 weeks and 3 dayes of gestation age with uterine prolapse and labor pain. She was prepared to Cesarian Section with normal lab analysis and was done emergency caesarean section and was born a baby boy with $2150 \mathrm{~g}$ and Apgar score10/10.
\end{abstract}

Keywords: Pregnancy, Uterine Prolapse

\section{Introduction}

Uterine prolapse refers to the downward displacement of the vaginal apex. The vaginal apex is either the uterus or cervix or in women who have done supracervical or total hysterectomy, the cervix or vaginal cuff (1). Another classification of pelvic organ prolapse (POP) is including: Cystocele, Rectocele, Entrocele, Apical compartment prolapse or uterine prolaple (our case), Uterine procidentia (1). This condition is made by stretching and weakening of connective tissues, Muscles and neural defects.

Risk factors for POP include high parity,advancing age and obesity (1). Women with POP were assessed using POPQuantitation system (Figure 1). There arennot any symptoms in women with mild uterine prolapse based on POP-Q system. Although pregnant women may present with new symptoms or an exacerbation of POP during pregnancy. Moderate and severe uterine prolapse may produce symptoms such as: (1)

- Feeling like sitting on a ball

- Vaginal bleeding or vaginal discharge

- Sexual Problems

- Protruding of the uterus or cervix from the vagina

- Heavy feeling in pelvis

- Constipation or obstipation

- Recurrent cyctitis

Causes of uterine prolapse in multiparouse women is truma to muscles (levator ani, superficial and deep perineal muscles) and ligaments (Cardinal and Uterisacral ligaments) during pregnancy and delivery that lead to prolapse. Risk of surgery due to POP is after first (fouthfold) and second birth (eightfold) and then increased less rapidly for next births (third; ninefold and forth;10fold)(1). However risk of POP after vaginal delivery is greater than cesarian section
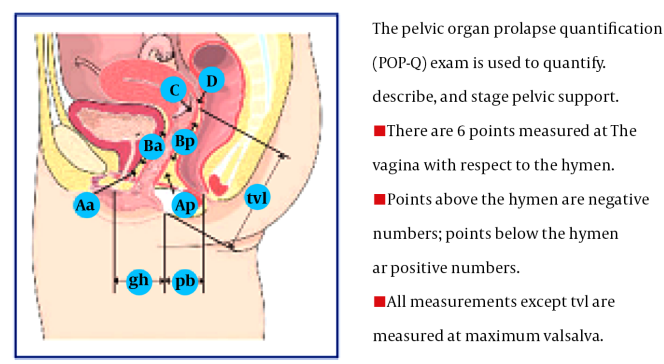

\begin{tabular}{|c|c|c|}
\hline Point & Description & Range of Values \\
\hline Aa & Anterior vaginal wall $3 \mathrm{~cm}$ prximal to the hymen & $-3 \mathrm{~cm} \mathrm{to}+3 \mathrm{~cm}$ \\
\hline Ba & Most distal position of the remaining upper anterior vaginal wall & $-3 \mathrm{~cm}$ to $+\mathrm{tvl}$ \\
\hline $\mathrm{C}$ & Most distal adge of oervix or vaginal cuff scar & \\
\hline D & Posterior fornix (N/A if post-hysterectomy) & \\
\hline Ap & Posterior vaginal wall $3 \mathrm{~cm}$ proximal to the hemen & $-3 \mathrm{~cm}$ to $+3 \mathrm{~cm}$ \\
\hline вр & Most distal position of the remaining upper posterior vaginal wall & $-3 \mathrm{~cm}$ to $+\mathrm{tvl}$ \\
\hline \multicolumn{3}{|c|}{$\begin{array}{l}\text { Genital hiatus (gh) - Measured from middle of eathernal urethral meatus to posterior midline hymer } \\
\text { Perineal (pb) - Measured from posterior margin of gh to middle of anal opening } \\
\text { Total vaginal lenght (tvl) - Depth of vagina when point } D \text { or } C \text { is reduced to normal position }\end{array}$} \\
\hline \multicolumn{3}{|c|}{ POP-Q Staging Criteria } \\
\hline Stage 0 & \multicolumn{2}{|l|}{$\mathrm{Aa}, \mathrm{Ap}, \mathrm{Ba}, \mathrm{Bp}=-3 \mathrm{~cm}$ and $\mathrm{C}$ or $\mathrm{D} \leq-(\mathrm{tvl}-2) \mathrm{cm}$} \\
\hline Stage I & \multicolumn{2}{|l|}{ Stage 0 criteria not met and leading adge $<-1 \mathrm{~cm}$} \\
\hline Stage II & \multicolumn{2}{|l|}{ Leading edge $\geq-1 \mathrm{~cm}$ but $\leq+1 \mathrm{~cm}$} \\
\hline Stage III & \multicolumn{2}{|l|}{ Leading edge $>+1 \mathrm{~cm}$ but $\leq+(\mathrm{tvl}-2) \mathrm{cm}$} \\
\hline Stage IV & \multicolumn{2}{|l|}{ Leading edge $\geq+(\mathrm{tvl}-2) \mathrm{cm}$} \\
\hline
\end{tabular}

REFERENCE: Bump RC, Maltiasson A. Bo K et al. The standardezation of terminology of female pehvic organ prolapsa and pelvic floor dyfunction. Am J Obstat Gynecol. 1996;176;175;13.

Figure 1. POP-Quantitation System 


\section{Case Presentation}

This study is about a 33-year-old Iranian (balouch lady) G5P4L4 who was reffered to the maternal ward of Emam Ali hospital of Zahedan city in the 35 weeks and 3 dayes of gestation with uterine prolapse and labor pain. Vaginal exam of the patient was dilatation $3-4 \mathrm{~cm}$, Effacement 40\%, Presentation part, Cephalic, Station, -3 and Amniotic sac, Intact. Laboratory investigations were normal. First delivery in this patient was after 39 weeks without any uterine prolapse and NVD, Second delivery was in 25 years old with Normal vaginal delivery without any information of POP from side of patient. The third and fourth were like the two pervious cases at 39 - 40 weeks. During fifth pregnancy she was without regular prenatal care (PNC) and experienced urinary incontinence and heaviness and moderate to high grade uterine prolapse(POP) after 30 weeks. She had tolerated this prolapsed. So after increasing the grade of prolapse and starting of labor pain, she came to maternal ward. There was a complete prolapse based on PAP-Q system. The Auther prepared her to CS with normal lab analysis and performed emergency cesarean section and was born a baby boy with $2150 \mathrm{~g}$ and Apgar score 10/10. She was discharged 2 days later healthy and requested her to come back after 2 weeks.

\section{Discussion}

Uterine prolapse as the common gynecologic problem is the descent of uterus, cervix or vaginal cuff. Pelvic organ prolapse (POP) affects millions of women (1), but this problem is rarely during pregnancy and this study has shown pregnant woman with uterine prolapse in Figures 2 and 3. Primary litratures (before 1970) has not determined the exact grade of prolapse but muliparous women were more common in the classification of uterine prolapse (Apical compartment prolapse) using the POP-Q evaluation $(2,3)$.

Multiple factors are usually involved in the production of uterine prolapse but the most prominent cause is pregnancy, or difficult delivery. However, it may also occur spontaneously, although very rarely, even in nulliparous women. In this study, The patient was grand multiparous (5th multiparous) and low culture and education and had have difficult delivery at home as well as poor PNC in past pregnancies and last pregnancy. If the patient had good PNC, she could receive pessary at low grade prolapse based on POP-Q system.

Pelvic floor muscle training (PFMT), Estrogen therapy and vaginal pessary are conservative management as the first line option for POP. And they reduce complications correlated with this condition. Complications such as recurrent cystitis, vaginal bleeding due to cervical ulcera-

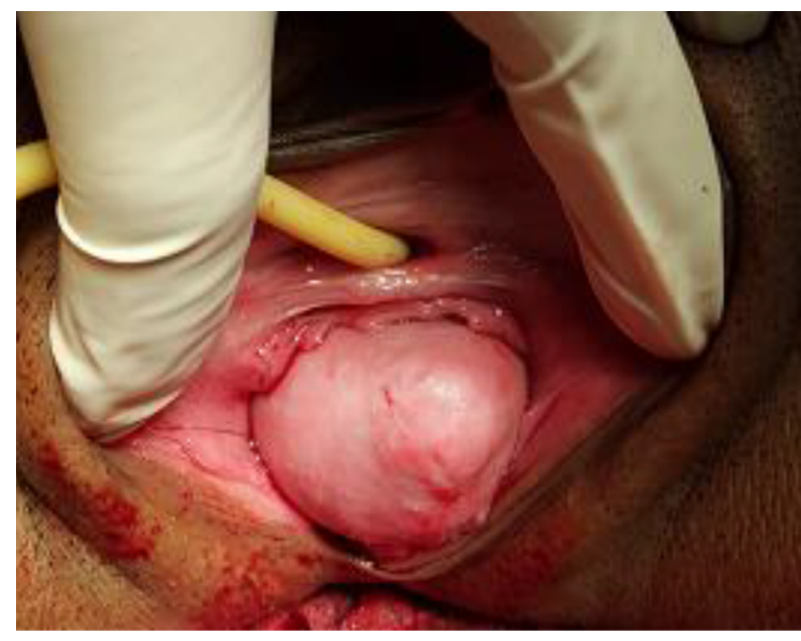

Figure 2. In the Operation Room

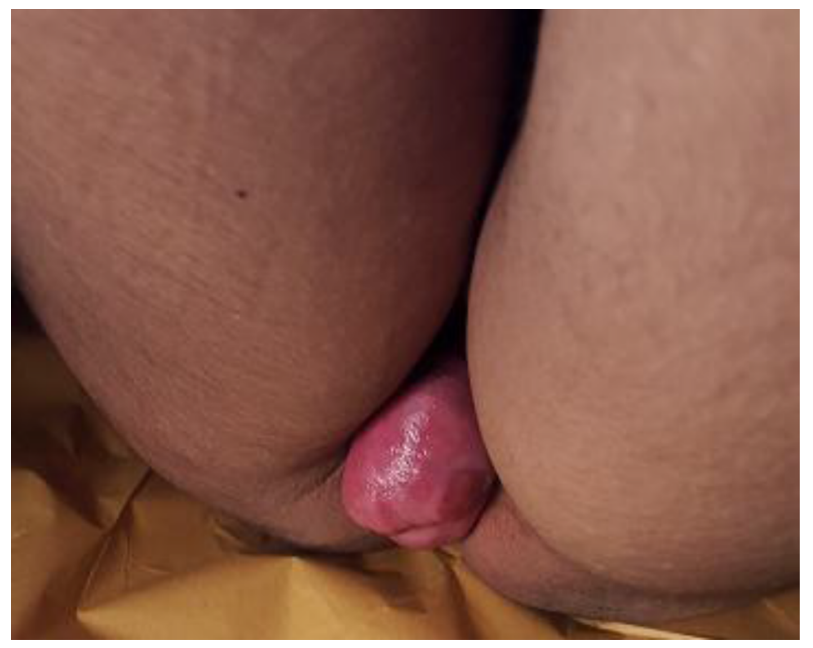

Figure 3. Three Months Post-Surgery

tion, vaginal discharge, urinary retention, abortion, preterm labor and even maternal death have been described (3). In an article recommended a vaginal pessary application during the first six months $(2,4)$. The Auther observed some of these complications like cervical ulceration with light symptoms of heaviness without pelvic pain. Although in a recent report, Eddib et al. managed a similar case with a vaginal delivery, As was said in all of the paperts, the auther also believes elective caesarean section near term because could be the safest delivery method in order to avoid a progression of the prolapse grade and uterine rupture or trauma (4)

In conclusion, natural pregnancy during uterine pro- 
lapse is possible and the management of uterine prolapse during labor should be done based on grade of the POP, Gestational age, Parity (5, 6).

A vaginal delivery can be done, but according many litratures, an elective caesarean section near term could be as a safe delivery option (7).

\section{References}

1. Uptodate Available from: https://www.Uptodate.com.

2. Jeng CJ, Lou CN, Lee FK, Tzeng CR. Successful pregnancy in a patient with initially procidentia uteri. Acta Obstet Gynecol Scand. 2006;85(4):501-2. doi: 10.1080/00016340600607529. [PubMed: $16612716]$.
3. Eddib A, Allaf MB, Lele A. Pregnancy in a woman with uterine procidentia: a case report. J Reprod Med. 2010;55(1-2):67-70. [PubMed: 20337211].

4. Guariglia L, Carducci B, Botta A, Ferrazzani S, Caruso A. Uterine prolapse in pregnancy. Gynecol Obstet Invest. 2005;60(4):192-4. doi: 10.1159/000087069. [PubMed: 16020934].

5. Chun SS, Park KS. Birth of a healthy infant after in vitro fertilization and embryo transfer in patient of total uterine prolapse. J Assist Reprod Genet. 2001;18(6):346-8. [PubMed: 11495412].

6. Bump RC, Mattiasson A, Bo K, Brubaker LP, DeLancey JO, Klarskov P, et al. The standardization of terminology of female pelvic organ prolapse and pelvic floor dysfunction. Am J Obstet Gynecol. 1996;175(1):10-7. [PubMed: 8694033].

7. Daskalakis G, Lymberopoulos E, Anastasakis E, Kalmantis K, Athanasaki A, Manoli A, et al. Uterine prolapse complicating pregnancy. Arch Gynecol Obstet. 2007;276(4):391-2. doi: 10.1007/s00404-007-0354-0. [PubMed: 17406876]. 